\title{
The Role of Cytologic Analysis in Follow-Up of Non-Muscle Invasive Urothelial Cell Carcinoma in Relation to Cystoscopic Biopsy
}

\section{Dalia M Badary ${ }^{1 *}$, and Reda $\mathrm{A}^{2}$}

${ }^{1}$ Pathology Department, Faculty of Medicine, Assuit University, Al-Gamaa street, Egypt

${ }^{2}$ Urology Department, Faculty of Medicine, Assiut University, Al-Gamaa street, Egypt

\begin{abstract}
Background: Bladder urothelial carcinoma has high recurrence rate so patients with bladder urothelial carcinoma have to be monitored thoroughly for disease recurrence, this makes bladder cancer one of the most expensive cancer types for the health care system. Voided urine cytology is the most commonly used noninvasive follow-up diagnostic tool. The purpose of this study was to assess the role of voided urine cytology for the follow-up of patients with non-muscle invasive urothelial carcinoma (NMIUC).

Materials and methods: In total, 200 patients were enrolled in this study. Both urine cytology and cystoscopy were done for each patient every three months and end-point of the surveillance was at 9 months after the first collection of urine and first cystoscopy done. In each time we correlate the findings of urine cytology and cystoscopy.

Results: The sensitivity of voided urine cytology was low while the specificity of voided urine cytology was high after their estimation every three months for nine months. The positive predictive value of voided urine cytology was 0.867 , while the negative predictive value was 0.919 at the end point of surveillance. None of the 180 patients with negative results of both cytology and cystoscopy developed recurrence for 6 months after initial diagnosis.

Conclusion: Cytology has higher specificity than sensitivity especially for high grade urothelial carcinoma and high predictive value but it still was not sufficiently good to be a substitute for cystoscopy. However, follow-up cystoscopy may be temporarily postponed for a period of 6 month if urine cytology is negative.
\end{abstract}

Keywords: Bladder transitional cell carcinoma; Urine cytology

\section{Introduction}

Carcinoma of the urinary bladder is the most prevalent cancer in most African countries. In Egypt, bladder cancer represents the most common malignancy among Egyptian males and previously has been attributed to Schistosoma infection, a major risk factor for squamous cell carcinoma (SCC). Recently, urothelial carcinoma (UC) incidence has been increasing while SCC has declined [1]. About $85 \%$ of patients with urothelial bladder carcinoma present with nonmuscle invasive urothelial tumours (NMIUC) at first presentation, whereas the remaining $15 \%$ of primary tumours are already muscle invasive (MIUC). After being removed by transurethral resection (TUR), NMIUC will recur in up to $70 \%$ of patients [2], and up to one third of pT1 tumours will eventually develop a progression to muscle invasive disease [3]. Patients with bladder cancer therefore have to be monitored thoroughly for disease recurrence and progression. This makes bladder cancer one of the most expensive cancer types for the health care system [4].

Early detection of recurrent cancer is crucial to improve the treatment outcome. Consequently, regular follow-up for patients with NMIUC is mandatory. The tension on patients and the burden on health-care providers for life-long follow-up are great. There are classical methods for follow-up purposes as urine cytology and regular cystoscopy. Although cystoscopic biopsy is the most accurate diagnostic tool for detection of recurrent cancer, and currently is the standard of choice [5], cystoscopy may still miss tiny tumors, and also lead to false-negative results. Also, importantly, cystoscopy is invasive, and associated with morbidity, which is the main reason preventing patients from being regularly followed-up. Voided urine cytology is the most commonly used noninvasive follow-up diagnostic tool [6]. In urine cytology, cells present in voided urine are examined and described as being positive or negative for the presence of malignant cells, atypical or having suspicious cells present [7].
The purpose of this study was to assess the clinical role of voided urine cytology for the follow-up of patients with non-muscle invasive urothelial tumours (NMIUC).

\section{Material and Methods}

From June 2015 to December 2016, 200 patients were enrolled in this prospective study. All patients did previous TUR and their biopsies referred to the Department of Pathology, Assuit University Hospital and diagnosed by histopathology as non-muscle invasive urothelial carcinoma of the bladder (All biopsies contain parts of muscle layer for correct assessment of tumor stage. Tumor staging and grading were done according to the AJCC/UICC TNM staging 2009 [8] and to the $2004 \mathrm{WHO}$ classification criteria for malignant tumors of the urinary tract [9].

Fresh urine samples were obtained in the early morning after the patient had voided the overnight urine and the samples were sent for cytology. These patients received cystoscopy when with urine cytology each three months till a closing point for this study, nine months from first urine cytology and cytoscopy. In each time, we compare results of both urine cytology and cystoscopy.

*Corresponding author: Dalia M Badary, Pathology Department, Assuit University, Al-Gamaa street, Egypt, Tel: 00201066189050; E-mail: hamasat82@yahoo.com

Received February 14, 2017; Accepted March 16, 2017; Published March 18, 2017

Citation: Badary DM, Reda A (2017) The Role of Cytologic Analysis in FollowUp of Non-Muscle Invasive Urothelial Cell Carcinoma in Relation to Cystoscopic Biopsy. J Mol Biomark Diagn 8: 326. doi: 10.4172/2155-9929.1000326

Copyright: @ 2017 Badary DM, et al. This is an open-access article distributed under the terms of the Creative Commons Attribution License, which permits unrestricted use, distribution, and reproduction in any medium, provided the original author and source are credited. 


\section{Cytology and pathology}

A urine sample was centrifuged, fixed over a glass slide, and stained for exfoliated cancer cell examination. A pathologist examined the slides using a method with internationally recognized exclusion and inclusion criteria. The report was divided into 3 categories as malignant, suspicious, or negative. For every cancer patient enrolled, the pathologic slides when the cancer diagnosis was first made were reviewed again to determine the grade and stage of the cancer.

\section{Statistical analysis}

The sensitivity was defined as the true positive cases subtracted from the positive bladder cancer cases. The specificity was defined as the true negative cases subtracted from the negative bladder cancer cases. The positive predictive value was defined as the proportion of cystoscopypositive patients among urine cytology positive patients. The negative predictive value was defined as the proportion of cystoscopy negative patients among urine cytology negative patients.

\section{Results}

Two hundred patients with non-muscle invasive urothelial tumors (NMIUC) (140 men and 60 women) completed the study. The mean age was 65 (range, 48 to 80 ) years. After first three months recurrent bladder urothelial carcinoma was discovered by both urine cytology and cystoscopy in 3 of them, while seven of them showed false positive in urine cytology and true negative in cystoscopy. After second three months, there were eight patients developed recurrent cancer in both cytology and cystoscopic biopsy and there were 12 patients with positive results of urine cytology, but showed negativity by cystoscopy. None of the 200 patients with negative voided urine cytology revealed evidence

\begin{tabular}{|c|c|c|}
\hline & Cystoscopy (+) & Cystoscopy (-) \\
\hline \multicolumn{3}{|c|}{ After first 3 months } \\
\hline Voided urine cytology (+) & 3 & 7 \\
\hline Voided urine cytology (-) & 0 & 190 \\
\hline \multicolumn{2}{|c|}{ After second 3 months } \\
\hline Voided urine cytology (+) & 8 & 12 \\
\hline Voided urine cytology (-) & 0 & 180 \\
\hline \multicolumn{2}{|c|}{ After third 3 months } \\
\hline Voided urine cytology (+) & 13 & 15 \\
\hline Voided urine cytology (-) & 2 & 170 \\
\hline
\end{tabular}

Table 1: Results of voided urine cytology and cystoscopy.

\begin{tabular}{|c|c|c|c|c|}
\hline & Sensitivity & $\begin{array}{c}\text { Specificity \% } \\
\text { (Number of cases/ } \\
\text { total number) }\end{array}$ & $\begin{array}{c}\text { Positive } \\
\text { predictive } \\
\text { value }\end{array}$ & $\begin{array}{l}\text { Negative } \\
\text { predictive } \\
\text { value }\end{array}$ \\
\hline \multicolumn{5}{|c|}{ After first 3 months } \\
\hline $\begin{array}{l}\text { Voided urine } \\
\text { cytology }\end{array}$ & $30.0(3 / 10)$ & $100.0(190 / 190)$ & $100.0(3 / 3)$ & $96.4(190 / 197)$ \\
\hline \multicolumn{5}{|l|}{$\begin{array}{l}\text { After second } 3 \\
\text { months }\end{array}$} \\
\hline $\begin{array}{l}\text { Voided urine } \\
\text { cytology }\end{array}$ & $40.0(8 / 20)$ & $100.0(180 / 180)$ & $100.0(8 / 8)$ & 93.8(180/192) \\
\hline \multicolumn{5}{|c|}{ After third 3 months } \\
\hline $\begin{array}{l}\text { Voided urine } \\
\text { cytology }\end{array}$ & $46.4(13 / 28)$ & $98.8(170 / 172)$ & $86.7(13 / 15)$ & $91.9(170 / 185)$ \\
\hline
\end{tabular}

Table 2: Sensitivity, specificity, positive predictive value and negative predictive value, of voided urine cytology and cystoscopy.

\begin{tabular}{|c|c|}
\hline Percent (Number of cases/total number) & Voided urine cytology \\
\hline Low grade urothelial carcinoma & $31.8(7 / 22)$ \\
\hline High grade urothelial carcinoma & $100.0(6 / 6)$ \\
\hline
\end{tabular}

Table 3: Sensitivity of voided urine cytology for different tumor grades. of recurrent bladder urothelial carcinoma with follow-up cystoscopy 3 and 6 months later. At the end-point of the surveillance we found that only 13 of them had bladder urothelial carcinoma according to both cytology and cystoscopy and only 2 of 172 patients with negative results of cytology had positive cystoscopic findings (Table 1).

Using the above data, the sensitivity of voided urine cytology was $30 \%, 40 \%$ and $46.4 \%$ at end of first 3 months, second 3 months and last 3 months respectively while the specificity was $100 \%, 100 \%$ and 98.8\% at end of first 3 months, second 3 months and last 3 months respectively. The positive predictive value of voided urine cytology was $100 \%$ in both times at first 6 months and $86.7 \%$ at the end point of surveillance. The negative predictive value was $96.4 \%$ at end of first 3 months, $93.8 \%$ at end of 6 months and $91.9 \%$ at 9 months from first voided urine taken and cystoscopy was done (Table 2).

As for the relationship between the pathological grading and the results of urine cytology done at the end point of surveillance, the pathological grade was low grade in 7 out of 22 patients and high grade in 6 out of 6 patients. Accordingly, the sensitivity of voided urine cytology to detect Low grade TCC was $31.8 \%$ and high grade was $100 \%$ (Table 3).

\section{Disscusion}

Bladder cancer is a common malignancy. Urinary bladder carcinoma is ninth in worldwide cancer incidence. It is the seventh most common malignancy in men and seventeenth in women [10]. Urothelial carcinoma of the bladder (UC) ranks 4th in incidence of all cancers in the developed world, bladder cancer has been the most frequently diagnosed cancer and the most common cause of death in men aged 20-44 years in Egypt [1].

After decades of investigation and research, Urothelial carcinoma of the bladder (UC) is still a difficult disease to diagnose in clinical practice and characterized by high recurrence rate, pathological progression and poor survival in advanced metastatic disease. Due to the long follow-up period and associated expenses of disease monitoring it is one of the most expensive cancers to manage. Local therapy and surveillance are the mainstays of management of early disease, whilst neoadjuvant chemotherapy, radical surgery and radiotherapy are effective in advanced disease [11]. The high recurrent rate challenges the quality of life and the prognosis of patients with urothelial carcinoma of the bladder (UC).

Before a thorough understanding of the mechanism for genetic prevention is available, the only way to improve the outcome is to detect the recurrent cancer as early as possible. In the 1940s, voided urine cytology was first introduced for the diagnosis of bladder cancer. The use of urine cytology to detect bladder cancer in patients who present with microhematuria has been frequently reported [12]. This is, in no small part, due to the intuitive attractiveness of a non-invasive, relatively inexpensive screening test for a lethal disease that can be obtained in the office or clinic setting without exposing the patient to the risks of invasive procedures, surgery, radiation or contrast exposure. Another theoretical advantage of urine cytology screening is the ability to rule out malignancy, not only reducing patient concern, but also promoting cost savings through the avoidance of invasive and radiological procedures [13]

For these benefits use of voided urine cytology in follow up patients with NMIUC deserves studying hoping to be useful follow up method to avoid high costs of invasive and radiological procedures and decrease burden on patients. 
Citation: Badary DM, Reda A (2017) The Role of Cytologic Analysis in Follow-Up of Non-Muscle Invasive Urothelial Cell Carcinoma in Relation to Cystoscopic Biopsy. J Mol Biomark Diagn 8: 326. doi: 10.4172/2155-9929.1000326

Unfortunately, we found the diagnostic capabilities of voided urine cytology are rather disappointing. Although the urine cytology has a high overall specificity $(98.8 \%)$ at the end point of surveillance, it has low overall sensitivity in detecting urothelial cancer (46.4\%), In other words, 2 bladder urothelial carcinomas out of 172 patients might have been missed using voided urine cytology alone., These results are in concurrence with other reports [14-16]. Also, Rosser and colleagues confirm the low sensitivity of urinary cytology at 33\% (88\% if atypia is considered positive) and the high specificity of urine cytology ranging from $67 \%(47 / 47+23)$ if atypia is considered positive to $100 \%$ (if atypia if considered negative) [17]. However, none of the 180 patients with negative voided urine cytology revealed evidence of bladder urothelial carcinoma with follow-up cystoscopy 6 months after initial diagnosis. It is thus suggested that cystoscopy might be omitted at least for a period of 6 months when urine cytology was negative. A longer observation period needs to be verified by further study.

According to this study, the negative and the positive predictive value of urine cytology test was high as measured $91.9 \%$ and $86.7 \%$ respectively at the end point of surveillance and these results close to results of previous studies $[13,18]$. Perhaps with its high documented positive predictive value (assuming atypia is not considered positive), positive urine cytology can be used to direct patients to operating room procedures, obviating the need for office cystoscopy since a biopsy and/or ureteroscopy would be needed as a supplement to surveillance cystoscopy.

Furthermore, there may be a role in using voided urine cytology in patients with a history of bladder urothelial carcinoma who are at risk for recurrence and disease progression.

The voided urine cytology can detect exfoliated cancer cells with a specific pathological appearance. Consequently, its results are poor for low-grade cancers which usually do not easily exfoliate cells [19]. This observation was again found in this study. As clearly illustrated in Table 3, there was only a $31.8 \%$ detection rate for low grade urothelial carcinoma with traditional urine cytology while $100 \%$ of high grade urothelial carcinoma detected by urine cytology and these results are similar to results of $[20,21]$.

From the previous results, we can't ignore the role of urine cytology in early detection of cancer recurrence especially it is considered the easiest non-invasive method for regular follow up with lowest costs but in sum, voided urine cytology does not obviate the need for cystoscopy.

\section{Conclusion}

Cytology has high specificity than sensitivity especially for high grade urothelial carcinoma and high predictive value but it still was not sufficiently good to be a substitute for cystoscopy. However, follow-up cystoscopy may be temporarily postponed for a period of 6 month if urine cytology is negative.

\section{References}

1. Fedewa SA, Soliman AS, Ismail K, Hablas A, Seifeldin IA et al. (2009) Incidence analyses of bladder cancer in the Nile delta region of Egypt. Cancer epidemio 33: $176-181$
2. Zaak D, Karl A, Knüchel R, Stepp H, Hartmann A, et al. (2005) Diagnosis of urothelial carcinoma of the bladder using fluorescence endoscopy. BJU Int 96: 217-222.

3. Shahin O, Thalmann GN, Rentsch C, Mazzucchelli L, Studer UE (2003) A retrospective analysis of 153 patients treated with or without intravesical bacillus Calmette-Guerin for primary stage T1 grade 3 bladder cancer: recurrence, progression and survival. J urol 169: 96-100.

4. Murta-Nascimento C, Schmitz-Dräger BJ, Zeegers MP, Steineck G, Kogevinas $\mathrm{M}$, et al, (2007) Epidemiology of urinary bladder cancer: from tumor development to patient's death. World J urol 25: 285-295.

5. Kriegmair M, Baumgartner R, Knüchel R, Stepp H, Hofstädter F, et al. (1996) Detection of early bladder cancer by 5 -aminolevulinic acid induced porphyrin fluorescence. J urol 155: 105-110.

6. Davis R, Jones JS, Barocas DA, Castle EP, Lang EK, et al. (2012) Diagnosis, evaluation and follow-up of asymptomatic microhematuria (AMH) in adults: AUA guideline. J urol 188: 2473-2481.

7. Curry JL, Wojcik EM (2002) The effects of the current World Health Organization/ international society of urologic pathologists bladder neoplasm classification system on urine cytology results. Cancer 96: 140-145.

8. Cheng L, Montironi R, Davidson DD, Lopez-Beltran A (2009) Staging and reporting of urothelial carcinoma of the urinary bladder. Mod Pathol 22: S70-S95.

9. Lopez-Beltran A, Montironi R (2004) Non-invasive urothelial neoplasms: according to the most recent WHO classification. Eur Urol 46: 170-176.

10. Malats N, Real FX (2015) Epidemiology of bladder cancer. Hematology/ oncology clinics 29: 177-189.

11. di Martino E, Tomlinson DC, Knowles MA (2012) A decade of FGF receptor research in bladder cancer: Past, present, and future challenges. Adv Urol.

12. Hoque MO, Begum S, Topaloglu O, Chatterjee A, Rosenbaum E, et al. (2006) Quantitation of promoter methylation of multiple genes in urine DNA and bladder cancer detection. J Natl Cancer Inst 98: 996-1004.

13. Trivedi D, Messing EM (2009) Commentary: The role of cytologic analysis of voided urine in the work-up of asymptomatic microhematuria. BMC urology 9: 13

14. Vlahou A, Schellhammer PF, Mendrinos S, Patel K, Kondylis FI, et al. (2001) Development of a novel proteomic approach for the detection of transitional cell carcinoma of the bladder in urine. Am J Pathol 158: 1491-1502.

15. Tilki D, Burger M, Dalbagni G, Grossman HB, Hakenberg OW, et al. (2011) Urine markers for detection and surveillance of non-muscle-invasive bladder cancer. Eur Urol 60: 484-492.

16. Wiener HG, Mian C, Haitel A, Pycha A, Schatzl G, et al. (1998) Can urine bound diagnostic tests replace cystoscopy in the management of bladder cancer? J Urology 159: 1876-1880.

17. Nakamura K, Kasraeian A, Iczkowski KA, Chang M, Pendleton J, et al. (2009) Utility of serial urinary cytology in the initial evaluation of the patient with microscopic hematuria. BMC urology 9: 12.

18. Pfister C, Chautard D, Devonec M, Perrin P, Chopin D, et al. (2003) Immunocyt test improves the diagnostic accuracy of urinary cytology: Results of a French multicenter study. J Urol 169: 921-924.

19. Turbat-Herrera EA, Colom $\mathrm{H}$ (2000) The dilemma of urinary cytology revisited. AJSP: Reviews \& Reports 5: 95-101.

20. Ellis WJ, Blumenstein BA, Ishak LM, Enfield DL (1997) Clinical evaluation of the BTA TRAK assay and comparison to voided urine cytology and the Bard BTA test in patients with recurrent bladder tumors. Urology 50: 882-887.

21. Potretzke AM, Knight BA, Vetter JM, Anderson BG, Hardi AC, et al. (2016) Diagnostic utility of selective upper tract urinary cytology: A systematic review and meta-analysis of the literature. Urology 96: 35-43. 